\title{
Effects of exchanging lactose for fat in milk replacer on ad libitum feed intake and growth performance in dairy calves
}

\author{
H. Berends, ${ }^{1} \oplus$ H. van Laar, ${ }^{1} \oplus$ L. N. Leal, ${ }^{1,2 *} \oplus$ W. J. J. Gerrits, ${ }^{2} \oplus$ and J. Martín-Tereso ${ }^{1} \oplus$ \\ ${ }^{1}$ Trouw Nutrition R\&D, PO Box 299, 3800 AG, Amersfoort, the Netherlands \\ ${ }^{2}$ Animal Nutrition Group, Wageningen University, PO Box 338, 6700 AH Wageningen, the Netherlands
}

\section{ABSTRACT}

The recent trend in the dairy industry toward ad libitum feeding of young calves merits reconsideration of calf milk replacer (CMR) formulations. Additionally, feed intake regulation in young calves provided with ad libitum milk and solid feeds is insufficiently understood. This study was designed to determine the effect of exchanging lactose for fat in CMR on voluntary feed intake and growth performance. Lactose was exchanged for fat on a weight/weight basis, resulting in different energy contents per kilogram of CMR. Thirty-two male calves $(1.7 \pm 0.12 \mathrm{~d}$ of age, $47.6 \pm$ $0.83 \mathrm{~kg}$ of body weight) were assigned to 1 of 16 blocks based on arrival date. Within each block, calves were randomly assigned to 1 of 2 treatments. The experimental period was divided into 4 periods. In period 1, until $14 \pm 1.7 \mathrm{~d}$ of age, calves were individually housed, restricted-fed their assigned CMR treatments at 2.5 to $3 \mathrm{~L}$ twice daily, and provided with unlimited access to water, chopped straw, and starter. In period 2, calves were group-housed with 8 calves per pen and received ad libitum access to their assigned CMR treatments, starter feed, chopped wheat straw, and water. During period 3, from 43 until $63 \mathrm{~d}$ of age, calves were weaned by restricting CMR allowance in 2 steps, maintaining access to all other feeds. All calves were completely weaned at d 64 of age and were monitored until $77 \mathrm{~d}$ of age (period 4). Measurements included the intake of all dietary components, body weight gain, and a selection of blood traits. Increasing fat content at the expense of lactose decreased CMR intake by $10 \%$, whereas total calculated metabolizable energy intake and growth remained equal between treatments. Total solid feed (starter and straw) consumption was not affected by CMR composition. These data indicate that calves fed

Received August 2, 2019.

Accepted December 22, 2019

*Corresponding author: Leonel.leal@trouwnutrition.com ad libitum regulate their CMR intake based on energy content. High-fat CMR increased plasma phosphate, nonesterified fatty acids, triglycerides, and bilirubin, whereas plasma glucose remained unchanged. Despite the limited animal numbers in the present experiment, there was a significant decrease in the total number of health events (mainly respiratory) requiring therapeutic intervention and in the total number of therapeutic interventions in calves fed high-fat CMR. Calves appeared to consume CMR based on energy content, with a difference in ad libitum intake proportional to the difference in energy content of the CMR, maintaining equal body weight gain and solid feed intake.

Key words: milk replacer, calf, lactose, fat, growth

\section{INTRODUCTION}

In recent years, driven by the promise of improved performance in later life (Bar-Peled et al., 1997; Bach, 2011, 2012; Soberon and Van Amburgh, 2013), high planes or even unrestricted levels of milk or calf milk replacer (CMR) supply have been a global trend in dairy calf nutrition. Some information is available on the effect of $\mathrm{CP}$ content for high planes of nutrition on later life performance (Raeth-Knight et al., 2009; Morrison et al., 2012). However, in practice, traditional low feeding levels of CMR are increased without any adjustment in composition. Increasing all nutrients (e.g., fat, lactose, minerals, and protein) to the same extent is practical but likely far from optimal to meet nutrient requirements for the new, increased growth rates. A balanced nutrient supply is desired to optimize resource use but also to minimize any risk of exceeding nutrient tolerance at digestive or postabsorptive levels. For example, oversupply of lactose can lead to problems with glucose homeostasis and digestion (Hof, 1980). With a high feeding plane, especially if supplied in 2 meals per day, calves are likely to face these problems, particularly in the first weeks of life.

One could argue that whole milk provides a biological reference for unrestricted CMR supply in early life. The 
advantages of improved performance in later life are indeed observed when shifting from traditional to high feeding levels of whole milk (Bar-Peled et al., 1997; Moallem et al., 2010; Korst et al., 2017). Compared with whole milk, conventional CMR formulations provide high levels of lactose ( $42-50 \%$ vs. $33-38 \%$ of DM) and low levels of fat (16-22\% vs. $30-40 \%$ of DM). The high lactose content in CMR is based partly on historical availability of milk by-products from cheese and butter production, which, combined with the traditional aim for high growth and low feed costs, discouraged fat inclusion in CMR formulation. This results in a lower dietary energy density and a lower energy:protein ratio of CMR compared with whole milk. Consequently, calves provided with whole milk generally retain more fat than calves provided with CMR (Bascom et al., 2007).

A generally accepted belief in calf rearing is that calves should grow lean to become productive dairy cows (Hill et al., 2008). However, the long-term effects of differences in body composition in early life as modified by nutrition have not yet been studied. It has been shown that de novo lipogenesis is limited in veal calves, with lactose being almost completely oxidized (van den Borne et al., 2007). Higher inclusion of fat in CMR increases fat deposition (Donnelly, 1983; Tikofsky et al., 2001; Bascom et al., 2007), as well as high nutrient supply (Diaz et al., 2001). Energy source in CMR also affects energy density, glucose supply, and osmotic value. A lower osmotic value, caused by exchanging lactose for fat, may ease the digestion of high volumes of milk, positively affecting gastrointestinal health (Wilms et al., 2019). Increasing energy density by a weight/weight exchange of lactose for fat increases the dietary energy:protein ratio, potentially affecting performance.

Research has shown that increasing overall nutrient supply early in life increases fat deposition in calves, yet this is still linked with improvements of later life performance in calves fed whole milk (Bar-Peled et al., 1997; Moallem et al., 2010; Korst et al., 2017). We therefore challenge the general belief of detrimental developmental effects of fat deposition in calves. With adipose tissue being recognized as a highly active metabolic and endocrine organ (Frayn et al., 2003), there could be a benefit in terms of energy homeostasis and the development of immune competence (Nonnecke et al., 2003). In addition, bovine calves evolved consuming milk with a higher energy:protein ratio and higher fat (e.g., 30-40\% of DM in whole milk) for up to 6 to 9 mo (Weary et al., 2008). Therefore, we evaluated the effect of dietary energy source (lactose vs. fat) in CMR on voluntary intake, growth performance, blood profiles, and selected health traits in rearing calves.

\section{MATERIALS AND METHODS}

Procedures complied with the Dutch Law on Experimental Animals and Directive 2010/63/EC (European Commission, 2010) and were accordingly approved by the Animal Care and Use Committee of Utrecht University.

\section{Animals, Housing, and Feeding}

A total of 32 male calves were gathered from neighboring dairy farms at between 0 and $3 \mathrm{~d}$ of age. At the dairy farm of origin, calves were handled according to a standardized protocol, including offering $6 \mathrm{~L}$ of colostrum for the first $24 \mathrm{~h}$ and thereafter offering meals of $2.5 \mathrm{~L}$ of a CMR containing $150 \mathrm{~g}$ of $\mathrm{CMR} / \mathrm{L}$ [Sprayfo Excellent, formulated to $22.5 \% \mathrm{CP}$ and $18.0 \%$ fat (fresh basis), Trouw Nutrition, Deventer, the Netherlands] twice daily. After arrival at the Calf Research Facility of Trouw Nutrition (Sint Anthonis, the Netherlands), calves were assigned to 1 of 16 blocks based on arrival date. Within each block, calves were randomly assigned to 1 of 2 treatments that differed in CMR formulation.

The experiment included 4 periods defining nutritional management from arrival to postweaning feeding. In period 1 , until $14 \pm 1.7 \mathrm{~d}$ of age, calves were housed in individual pens $(1.22 \times 2.13 \mathrm{~m})$ on a bedding of flax straw. During this period, calves were fed their assigned CMR formulation, restricted to $2.5 \mathrm{~L}$ twice daily until 7 $\mathrm{d}$ of age and 3.0 L twice daily between 7 and $14 \mathrm{~d}$ of age, and had unlimited access to water, straw (5-cm chop length), and a starter (5-mm pellet; For Farmers, Helmond, the Netherlands; Table 1), provided in buckets. For period 2, calves were group-housed with 4 blocks per pen $(8$ calves $)$. Group pens measured $5.0 \times 5.9 \mathrm{~m}$ with a flax straw-bedded resting area $(5.0 \times 2.8 \mathrm{~m})$ and rubber slatted floors in front of the feeders. In group pens, calves received their respective CMR treatment with ad libitum access via automated milk dispensers (C1000, Förster-Technik, Engen, Germany), starter via automated feeders (DeLaval, Tumba, Sweden), chopped wheat straw via automated feeders (CRFI, Biocontrol, Rakkestad, Norway), and water via automated bowls (Förster-Technik). The 2 experimental milk replacers were available in each of the 4 pens and supplied to the calves individually according to treatment by means of electronic recognition. Milk replacers (Table 1) were supplied ad libitum at $150 \mathrm{~g} / \mathrm{L}$, with the minimal time interval between 2 meals set at $1 \mathrm{~h}$, meal size set at a minimum of $0.5 \mathrm{~L}$ and a maximum of $2.0 \mathrm{~L}$, and the maximum drinking speed set at $0.3 \mathrm{~L} / \mathrm{min}$. Drinking speed was set following the ad libitum study of Webb et al. (2014), in which drinking speed was based on calves' need to suck and set to minimize nonnutritive suck- 
Table 1. Analyzed and estimated nutrient composition ( $\mathrm{g} / \mathrm{kg}$ of DM unless otherwise noted) of both calf milk replacers (CMR), starter feed concentrate, and straw used in the study

\begin{tabular}{lcccc}
\hline Item & High-fat CMR & High-lactose CMR & Concentrates & Straw \\
\hline DM (g/kg of product) & 972 & 968 & 875 & 916 \\
CP & 236 & 228 & 203 & $<40$ \\
Crude fat & 311 & 205 & 34 & 11 \\
Crude fiber & - & - & 90 & 429 \\
Lactose & 343 & 77 & 72 & - \\
Crude ash & - & - & 258 & - \\
Starch & 5.17 & 4.69 & 2.98 & - \\
ME ${ }^{1}$ Mcal/kg of DM) & 45.6 & 48.6 & 72.0 & - \\
CP:ME ratio & & & -
\end{tabular}

${ }^{1}$ Calculated ME for calf milk replacer $(\mathrm{Mcal} / \mathrm{kg})=[0.057 \times \mathrm{CP}(\%)+0.092 \times$ crude fat $(\%)+0.0395 \times$ lactose (\%)] $\times 0.93(\mathrm{NRC}, 2001)$. For starter feed, ME value was calculated based on NRC (2001) ME table values for the raw materials and applying the equation for calf starters.

ing (Haley et al., 1998), which was reported to affect satiety signals (de Passillé and Rushen, 1997). During period 3, from 49 until $63 \mathrm{~d}$ of age, calves were weaned in 2 steps. From 49 to $55 \mathrm{~d}$ of age, the maximum daily consumption was set at $8 \mathrm{~L}$ with a minimum time interval of $3 \mathrm{~h}$ between visits to the feeder. From 56 to 63 d of age, the maximum daily consumption was set at 4 $\mathrm{L}$ with a minimum time interval of $5 \mathrm{~h}$ between visits to the feeder. Period 4 started when all calves were weaned at $63 \mathrm{~d}$ of age and monitored until $77 \mathrm{~d}$ of age.

Within each block, calves were randomly assigned to either a high-lactose (HL) CMR or a high-fat (HF) CMR. Fat and lactose were exchanged on a weight/ weight basis based on spray-dried fat kernels, with the fat being one-third coconut oil and two-thirds palm oil. The rest of the CMR formulation parameters remained unchanged (Table 1). Calculated ME (cME) content of the CMR was calculated as (NRC, 2001)

$$
\begin{gathered}
\operatorname{cME}(\mathrm{Mcal} / \mathrm{kg})=[0.057 \times \mathrm{CP}(\%)+0.092 \\
\times \text { crude fat }(\%)+0.0395 \times \text { lactose }(\%)] \times 0.93 .
\end{gathered}
$$

Because of the weight/weight exchange of lactose for fat, the CP:cME ratio of the CMR was different (45.6 and $48.6 \mathrm{~g}$ of $\mathrm{CP} / \mathrm{Mcal}$ for $\mathrm{HF}$ and HL, respectively). The HL treatment aimed to represent present CMR general practice. The HF treatment was designed to be close to the fat content found in whole milk. The cME content of starter feed was calculated based on NRC (2001) ME table values for the raw materials and applying the equation for calf starters. Minimum barn temperature was $15^{\circ} \mathrm{C}$, and heaters were activated when necessary. Calves were exposed to daylight and artificial light from 0600 to $2200 \mathrm{~h}$ and to a night light.

\section{Measurements and Chemical Analysis}

The CMR were sampled right after production in the factory. Concentrates and straw were sampled at arrival on the farm. All feeds were analyzed for moisture content (EC 152/2009; European Commission, 2009), CP content (Dumas method: Etheridge et al., 1998), crude fat content using hydrochloric acid pretreatment and petroleum extraction (EC 152/2009; European Commission, 2009), and crude ash content (EC 152/2009; European Commission, 2009). Concentrate was also analyzed for starch content as described by Rijnen et al. (2001), and calf milk replacer was also analyzed for lactose content (EEG 71/250/EEG; European Commission, 1971).

Health was checked by caretakers daily, and in case of any sign of disease that could be recognized, a veterinarian protocol was followed (see Supplemental File S1; https://doi.org/10.3168/jds.2019-17382). If the symptoms were not recognized, a veterinarian was consulted. Body weight was measured at the day of arrival and thereafter weekly. Intake of CMR, water, concentrates, and straw was recorded manually for each individual calf during period 1 and thereafter via automated feeding systems.

Blood samples were taken from the jugular vein at the end of periods 1,2 , and 4 (at 14, 48, and $77 \mathrm{~d}$ of age) at $1000 \mathrm{~h}$. Samples were directly shipped for analysis at the routine veterinary laboratory of GD Animal Health (Deventer, the Netherlands). All analyses (except for triglycerides) performed at the laboratory were accredited by the Dutch Accreditation Council (Utrecht, the Netherlands). Blood cell traits were analyzed using a hematology analyzer. Erythrocytes, mean corpuscular volume, thrombocytes, and leucocytes were determined using impedance spectroscopy; monocytes were determined using flow cytometry; and hemoglobin was determined using photometry. Hematocrit, mean corpuscular hemoglobin, and mean corpuscular hemoglobin concentration were calculated from the abovementioned traits. All other traits were analyzed using a routine chemistry analyzer. The hemolysis index of samples was analyzed by UV spectrometry. Plasma glu- 
cose was determined with an enzymatic method based on hexokinase. Colorimetric methods were used to analyze serum calcium, phosphorus, and bilirubin (dimethyl sulfoxide method), plasma total protein (Biuret method), and albumin (bromocresol green method). Plasma chloride, sodium, and potassium concentrations were analyzed with an ion-specific electrode. Plasma urea, nonesterified fatty acids (NEFA), triglycerides, and creatinine were analyzed using enzymatic methods. Alkaline phosphatase, aspartate aminotransferase, gamma-glutamyl transferase, and creatine phosphokinase were analyzed using enzymatic methods according to the International Federation of Clinical Chemistry and Laboratory Medicine (IFCC) reference procedures for the measurement of catalytic activity concentrations of enzymes at $37^{\circ} \mathrm{C}$. Plasma lactate dehydrogenase and alanine aminotransferase were analyzed enzymatically using modified IFCC methods at $37^{\circ} \mathrm{C}$. Plasma glutamate dehydrogenase was analyzed using an enzymatic method (Deutsche Gesellschaft für Klinische Chemie method). Albumin and globulin fractions were analyzed using capillary electrophoresis. The albumin:globulin ratio was subsequently calculated from these measurements.

\section{Statistical Analysis}

For all statistics, SAS (version 9.4, SAS Institute Inc., Cary, NC) was used. Treatment averages were presented as predicted means and their standard error of the mean. For all traits except blood traits, differences were considered significant at $P \leq 0.05$. For blood traits, multiple comparisons were made at different time points, but also for multiple (32) traits measured in blood, there was an increased risk for type I errors (Benjamini and Hochberg, 1995). To reduce this risk for blood traits, we decided to consider differences only at $P<0.01$. When model residuals were not normally distributed, data were transformed (log, quadratic, inverse, and sine) to obtain homogeneity of variance. In that case, data were presented as nontransformed means with their standard error of the mean.

For each period ( 1 to 4 ), intakes and gain were averaged over period and analyzed with PROC MIXED, with CMR treatment as a fixed effect, initial BW as a covariable, and block as a random variable. Feed conversion was analyzed for both total DMI and DM from milk intake, with the same model and without initial BW as a covariable due to a lack of significance of this factor. Calf was considered the experimental unit.

For graphical display, BW and feed intakes were analyzed longitudinally using PROC MIXED, with treatment, time, and treatment $\times$ time interaction as a fixed effects, initial BW as a covariable, with and without block as a random effect, and with observations taken on the same group of calves in time (wk 1 to 11) included as repeated observations. Conceptually, the covariance structure of a trial with 4 periods with different nutritional management, where especially in wk 1 and 2 calves have increased occurrence of diarrhea compared with the following weeks, would be unstructured. If the model with an unstructured covariance matrix converged, the model with or without block was selected based on the lowest Akaike information criterion. If no unstructured model converged, then the model (with or without block) that did converge with the lowest Akaike information criterion was chosen. Covariance matrices that were tested were autoregressive (1), Toeplitz, antedependence, and compound symmetry with or without a heterogeneous variance. Differences between treatments per time point were determined using the LSMEANS SLICE statement.

Blood data were analyzed using PROC MIXED, with treatment, time, and treatment $\times$ time interaction as fixed effects, block as a random effect, and time (3 time points) as a repeated effect with autoregressive (1) covariance matrix. Differences between treatments per time point were determined using the LSMEANS SLICE statement. Count data were analyzed using PROC GLIMMIX, where a negative binomial distribution and a logit link were included and the effect of block was not included.

\section{RESULTS}

\section{Intake and Growth Performance}

Body weight was not affected by dietary treatment over the whole period except at wk 4, where HF cows had a lower BW (Figure 1). Similarly, ADG (Table 2) remained unaffected by treatment, with a tendency $(P$ $=0.06$ ) for a higher ADG in period 4 in animals that had previously been fed HF. Total voluntary consumption of HL CMR was greater $(P<0.05)$ than that of HF CMR (Table 2), mostly due to a higher HL intake in period 2 (Table 2; Figure 2). Overall starter intake between treatments (Table 2; Figure 3) and straw intake between treatments (Table 2) were not different, although straw intake was marginally $(27 \mathrm{~g} / \mathrm{d})$ but significantly $(P<0.05)$ greater for HL in period 3. During period 1 , cME intake for HF was greater $(P<0.05)$ than for HL, which was consistent with the increased cME content in the HF CMR. However, as a result of the higher CMR intake in period 2, cME intake was not significantly different during period 2 . There was no difference in cME intake in periods 3 and 4 as well as for the total experiment. When analyzed per week, cME intake differed at 4 and 5 wk of age (Figure 4). 


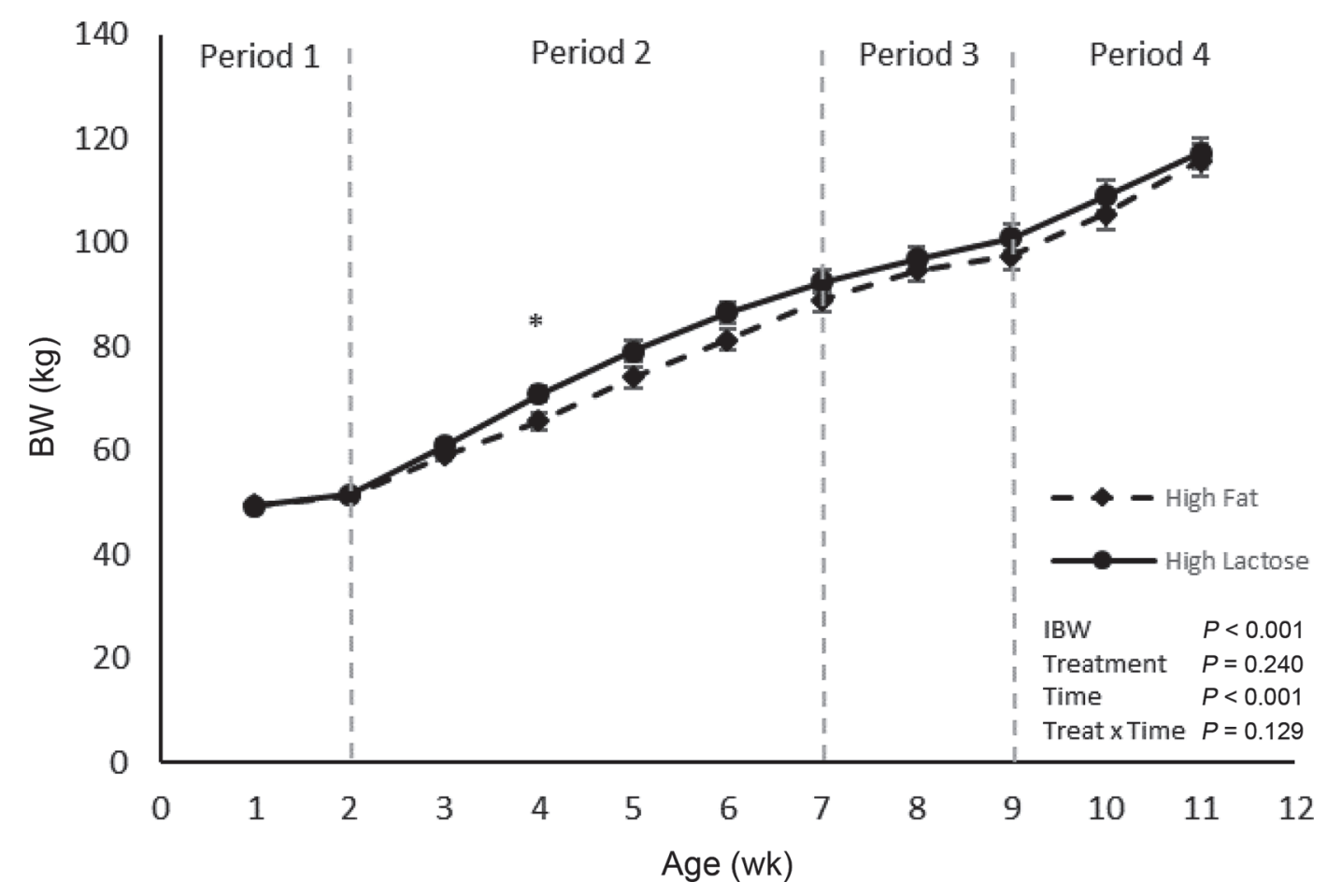

Figure 1. Development of BW of calves $(\mathrm{n}=32)$ fed a high-fat (dashed) or a high-lactose (solid) calf milk replacer (CMR) across periods 1 to 4. Asterisks indicate differences $(P<0.05)$ between the 2 treatments (unstructured covariance matrix, with random block effect). Period 1 : CMR restricted; period 2: CMR ad libitum; period 3: weaning; period 4: postweaning. IBW = initial BW. Error bars indicate SEM.

Feed conversion ratio based on total DMI was not different between treatments, although it was numerically lower for HF. When calculated based on DMI from CMR only, total feed conversion ratio and feed conversion ratio for period 2 were lower $(P<0.05)$ for HF than for HL. This was caused by the lower DMI for $\mathrm{HF}$, with a similar growth rate.

\section{Health Observations}

Plasma IgG at arrival averaged 1,673 $\pm 150.0 \mathrm{mg} / \mathrm{dL}$ and was not different between treatments $(P>0.05)$. Use of medication was generally high compared with the facility reference, especially for lung infections. In retrospect, the ventilation was considered not optimal and sometimes ineffective, with substantial time periods of high relative humidity (>80\%). A total of 52 health events required therapeutic intervention. Of these health events, $69.2 \%$ were lung-related conditions, $9.6 \%$ were joint infections, $9.6 \%$ were ear infections, $7.7 \%$ were cases of severe diarrhea, $1.9 \%$ were navel infections, and $1.9 \%$ were undefined cases of fever. Numerically, there were 11 and 25 treatments for lung-related issues in HF cows and HL cows, respectively, and each treatment had 2 treated diarrhea cases.
The average number of days of therapeutic intervention was $3.9 \mathrm{~d}$ per calf. Calves fed the HF CMR had a significantly lower number of days of therapeutic intervention, number of therapeutic interventions, and number of disease events that needed therapeutic intervention compared with HL cows (Table 3). In the experimental period, HL cows showed a 2.5 -fold higher incidence of days of therapeutic intervention, and the number of therapeutic interventions and disease events was more than doubled compared with HF cows.

\section{Blood Traits}

The effect of CMR formulation on selected blood traits was evaluated at the end of periods 1,2 , and 4 (14, 42, and $77 \mathrm{~d}$ of age; Tables 4, 5, and 6). Plasma phosphate, NEFA, and triglycerides were increased $(P$ $<0.01)$ in calves fed HF across all ages. Bilirubin concentration in HF cows was higher $(P<0.01)$ in periods 1 and 2 , whereas the treatment $\times$ time interaction $(P$ $<0.01)$ indicated that this effect was no longer present in period 4. Plasma levels of aspartate aminotransferase and glutamate dehydrogenase were lower $(P<0.01)$ in calves provided HF in period 4; however, there was no overall treatment effect nor an interaction $(P>0.01)$. 
Table 2. Least squares means for performance, intakes, and feed conversion ratio for periods 1 through 4 as well as the total trial for calves fed either a high-fat (HF) or a high-lactose (HL) calf milk replacer

\begin{tabular}{|c|c|c|c|c|c|}
\hline \multirow[b]{2}{*}{ Item } & \multicolumn{4}{|c|}{ Period $^{1}$} & \multirow{2}{*}{$\begin{array}{c}\text { Total } \\
\text { trial }\end{array}$} \\
\hline & 1 & 2 & 3 & 4 & \\
\hline \multicolumn{6}{|l|}{ ADG $(\mathrm{kg} / \mathrm{d})$} \\
\hline $\mathrm{HF}$ & 0.278 & 1.069 & 0.609 & 1.337 & 0.896 \\
\hline HL & 0.312 & 1.127 & 0.597 & 1.149 & 0.888 \\
\hline SEM & 0.039 & 0.051 & 0.063 & 0.077 & 0.032 \\
\hline HF vs. HL ( $P$-value) & 0.507 & 0.430 & 0.855 & 0.060 & 0.848 \\
\hline Initial BW ( $P$-value $)$ & 0.554 & 0.017 & 0.076 & 0.220 & 0.003 \\
\hline \multicolumn{6}{|l|}{ Intake $(\mathrm{kg}$ of $\mathrm{DM} / \mathrm{d})$} \\
\hline \multicolumn{6}{|l|}{ Milk replacer } \\
\hline $\mathrm{HF}$ & 0.809 & 1.148 & 0.683 & $\mathrm{NA}^{2}$ & 0.800 \\
\hline HL & 0.797 & 1.300 & 0.664 & NA & 0.861 \\
\hline SEM & 0.011 & 0.040 & 0.044 & NA & 0.020 \\
\hline HF vs. HL ( $P$-value $)$ & 0.422 & 0.012 & 0.534 & NA & 0.045 \\
\hline Initial BW ( $P$-value $)$ & 0.003 & 0.009 & 0.228 & NA & 0.003 \\
\hline \multicolumn{6}{|l|}{ Starter feed } \\
\hline $\mathrm{HF}$ & 0.010 & 0.074 & 0.466 & 1.905 & 0.463 \\
\hline $\mathrm{HL}$ & 0.017 & 0.056 & 0.538 & 1.980 & 0.482 \\
\hline SEM & 0.007 & 0.009 & 0.077 & 0.144 & 0.041 \\
\hline HF vs. HL ( $P$-value $)$ & 0.475 & 0.051 & 0.387 & 0.665 & 0.673 \\
\hline Initial BW ( $P$-value) & 0.814 & 0.544 & 0.367 & 0.185 & 0.212 \\
\hline \multicolumn{6}{|l|}{ Straw } \\
\hline $\mathrm{HF}$ & NA & 0.014 & 0.067 & 0.179 & 0.052 \\
\hline HL & NA & 0.012 & 0.094 & 0.175 & 0.054 \\
\hline SEM & NA & 0.002 & 0.008 & 0.013 & 0.004 \\
\hline HF vs. HL ( $P$-value $)$ & NA & 0.536 & 0.008 & 0.812 & 0.535 \\
\hline Initial BW ( $P$-value $)$ & NA & 0.049 & 0.007 & 0.019 & 0.005 \\
\hline \multicolumn{6}{|l|}{ Calculated ME (Mcal/d) } \\
\hline $\mathrm{HF}$ & 4.21 & 6.15 & 4.92 & 5.72 & 5.51 \\
\hline HL & 3.78 & 6.24 & 4.69 & 5.90 & 5.46 \\
\hline SEM & 0.06 & 0.19 & 0.23 & 0.42 & 0.16 \\
\hline HF vs. HL ( $P$-value) & $<0.0001$ & 0.752 & 0.36 & 0.714 & 0.771 \\
\hline Initial BW ( $P$-value $)$ & 0.008 & 0.008 & 0.386 & 0.228 & 0.005 \\
\hline \multicolumn{6}{|l|}{ Feed conversion $(\mathrm{kg} / \mathrm{kg})$} \\
\hline \multicolumn{6}{|l|}{ Total DMI based } \\
\hline $\mathrm{HF}$ & 4.49 & 1.16 & 2.97 & 1.48 & 1.43 \\
\hline HL & 5.7 & 1.22 & 2.38 & 2.01 & 1.51 \\
\hline SEM & 1.74 & 0.03 & 0.71 & 0.26 & 0.04 \\
\hline HF vs. HL ( $P$-value) & 0.634 & 0.154 & 0.560 & 0.111 & 0.144 \\
\hline Initial BW ( $P$-value $)$ & $\mathrm{NT}^{3}$ & NT & NT & NT & NT \\
\hline \multicolumn{6}{|l|}{ Milk replacer DMI based } \\
\hline $\mathrm{HF}$ & 4.46 & 1.09 & 1.85 & NA & 0.90 \\
\hline HL & 5.64 & 1.17 & 1.41 & NA & 0.98 \\
\hline SEM & 1.74 & 0.03 & 0.47 & NA & 0.03 \\
\hline HF vs. HL ( $P$-value $)$ & 0.641 & 0.014 & 0.510 & NA & 0.045 \\
\hline Initial BW ( $P$-value $)$ & NT & NT & NT & NT & NT \\
\hline
\end{tabular}

${ }^{1}$ Periods reflect different strategies for calf milk replacer (CMR) supply. Period 1: CMR restricted; period 2: CMR ad libitum; period 3: weaning; period 4: postweaning.

${ }^{2}$ Not available.

${ }^{3}$ Not tested.

Finally, hemolysis was greater $(P<0.01)$ in period 2 in calves fed HF CMR.

\section{DISCUSSION}

\section{Energy Source and Intake Response}

The rates of BW gain observed in the current study were at the higher end of the range observed in previ- ous studies where calves were exposed to high planes or ad libitum provision of milk or CMR (Moallem et al., 2010; MacPherson et al., 2016; de Paula et al., 2017; Korst et al., 2017). In period 2, intake of the HL CMR was $13 \%$ greater. From a macronutrient perspective, this is supported by earlier findings of Moallem et al. (2010), who observed a 9.2\% higher intake of CMR that had $13 \%$ fat and $23.7 \%$ protein compared with whole milk that had $29.4 \%$ fat and $25.9 \%$ protein. In 


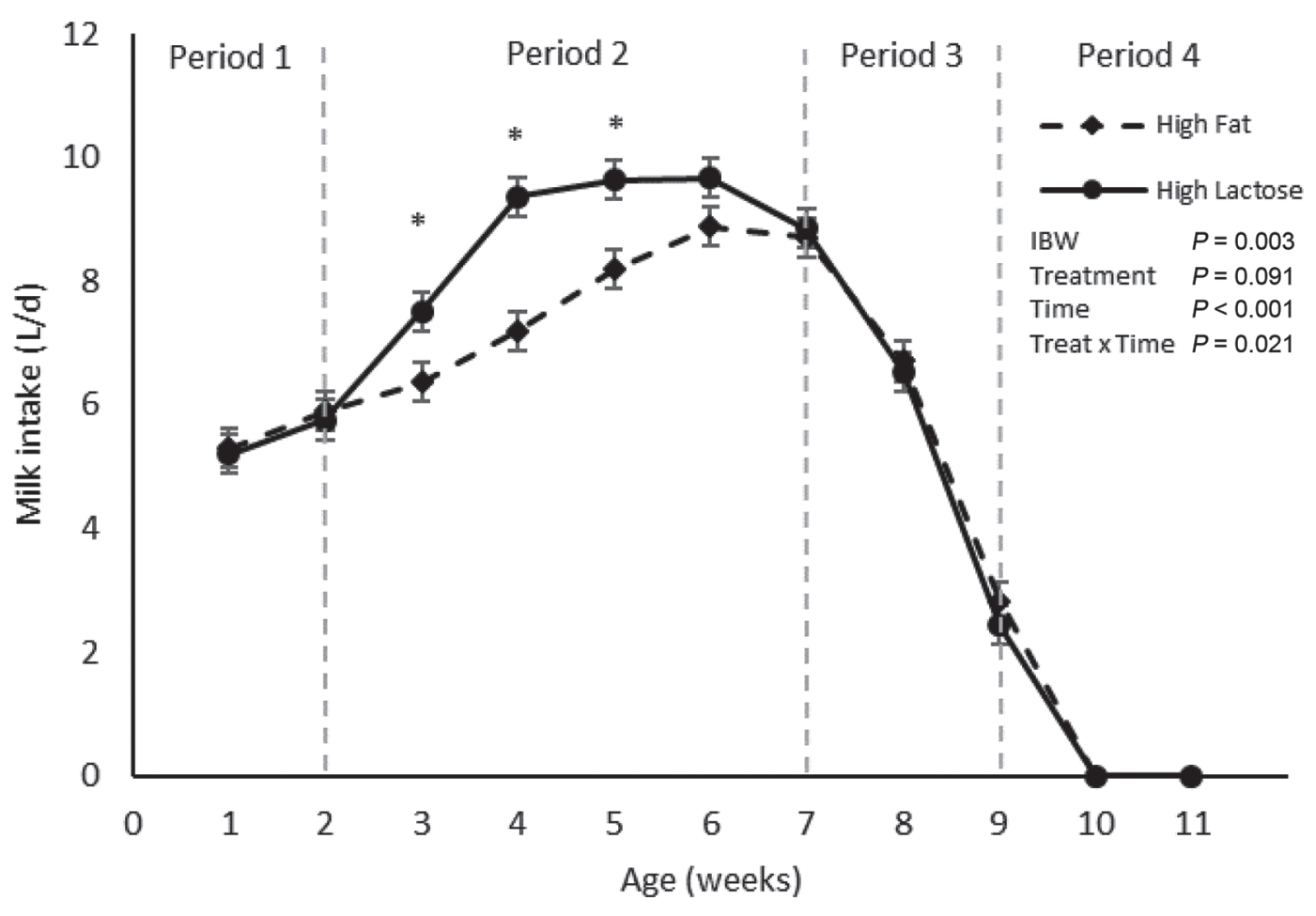

Figure 2. Weekly voluntary milk intake of calves $(\mathrm{n}=32)$ fed a high-fat (dashed) or a high-lactose (solid) calf milk replacer $(\mathrm{CMR})$ across periods 1 to 4 . Asterisks indicate differences $(P<0.05)$ between the 2 treatments (Toeplitz covariance matrix, without a block effect). Period 1: CMR restricted; period 2: CMR ad libitum; period 3: weaning; period 4: postweaning. IBW = initial BW. Error bars indicate SEM.

that study, calves were allowed to freely consume whole milk or CMR during 2 occasions of 30 min per day. For both studies, this could be interpreted as a reflection of energy intake regulation. Because energy intake was identical and CMR intakes were different between treatments in the current study, it seems that energy supply was regulating CMR intake. In adult ruminants, distension of the reticulorumen is considered to be the major regulator of satiety and a determinant of voluntary feed intake (Allen, 1996), but this should not be a relevant factor in the young calves of this study. Generally, the absorption of metabolic fuels drives satiety. Cholecystokinin secreted from the gastrointestinal tract is a short-term regulator of intake via its receptors. Leptin is apparent in the long term, and secretion of gastric leptin is caused by an increased cholecystokinin secretion stimulated by feeding (Bado et al., 1998). Interestingly, the expression of cholecystokinin and leptin receptors throughout the gastrointestinal tract of calves increases with age and the transition from milk to solid feed (Yonekura et al., 2002). In calves, rumen distension limitations are circumvented as milk bypasses the rumen with the esophageal groove reflex. Although it is known that weaned calves show large variation in feed preferences (Atwood et al., 2001), there is a lack of information on diet-related factors involved in feed intake regulation in young calves fed milk and solid diet components because they have traditionally been feed restricted. Given the global trend toward ad libitum nutrient supply in early life, this field is becoming more relevant. Feed intake regulation in calves may be driven by the availability of specific nutrients and may depend on the choice of ration components available. In a study where calves had ad libitum, free-choice access to milk replacer, water, hay, barley straw, concentrate, and corn silage, it was shown that dietary bulkiness, energy intake from CMR, or starter intake could not explain voluntary intake but that calves were consuming diets with a similar energy: protein ratio (Berends et al., 2016). The absence of a difference in starter intake between treatments in the current study was in line with earlier findings (Jaster et al., 1992; Hill et al., 2008; Esselburn et al., 2013) and suggests that solid feed intake in the presence of ad libitum milk or ad libitum CMR was regulated by rate of rumen development (Meale et al., 2017), distension, or natural preference. We speculate that metabolic satiety and physical satiety are regulated differently, although for mature cows indications for this can be found in Allen (2014). The observed intake of starter 


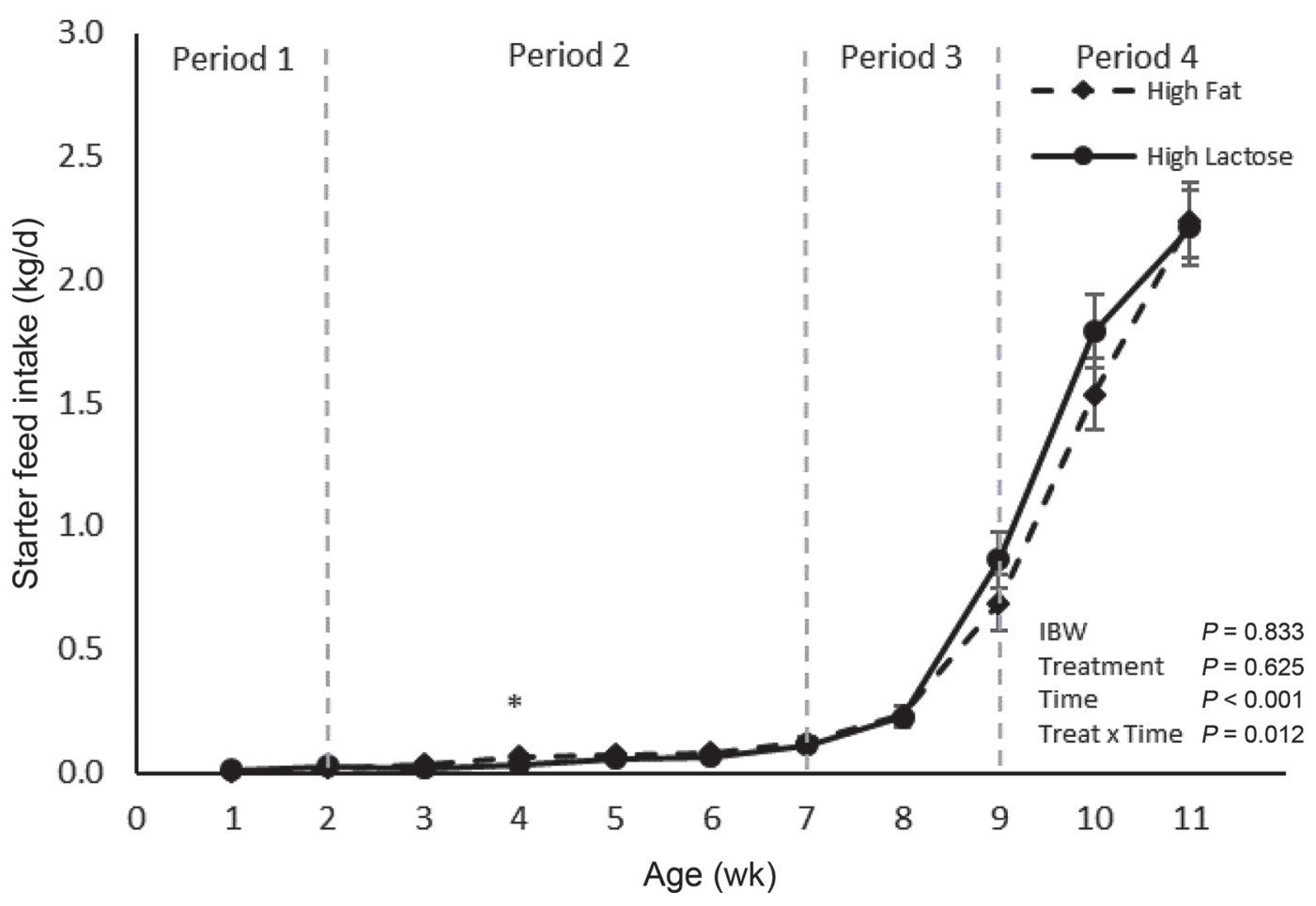

Figure 3. Weekly starter intake of calves $(\mathrm{n}=32)$ fed a high-fat (dashed) or a high-lactose (solid) calf milk replacer (CMR) across periods 1 to 4 . Asterisks indicate significant differences $(P<0.05)$ between the 2 treatments (unstructured covariance matrix, without block effect). Period 1: CMR restricted; period 2: CMR ad libitum; period 3: weaning; period 4: postweaning. IBW = initial BW. Error bars indicate SEM.

was substantially lower than when milk or CMR intake is restricted, and current values are well in line with other studies where milk was provided ad libitum (Khan et al., 2011, 2016).

In the current study design, the difference in energy content in dietary treatments was associated with a difference in protein:energy ratio as a consequence of the weight/weight exchange of energy sources. Protein intake was numerically lower (data not shown) for calves provided with an HF CMR compared with calves provided with an HL CMR, and a lower plasma urea was observed for $\mathrm{HF}$ at the end of periods 2 and 4 . Unlike other species, both protein and energy are always limiting growth in calves (Gerrits, 2019). At a similar energy intake this reduced protein intake did not result in a lower ADG, yet animals might have responded to higher protein levels; in Bartlett et al. (2006), higher $\mathrm{CP}$ levels were required for animals on high feed intake. We have not studied the effect of CMR energy source on digestion or on body composition. From earlier studies, it could be expected that higher inclusion of fat in CMR would have increased fat deposition (Donnelly, 1983; Tikofsky et al., 2001; Bascom et al., 2007; Hill et al., 2008), thus potentially retaining more energy at similar weight gain.

\section{Health Observations}

In the current experiment, we exchanged lactose for fat. We did not monitor fecal consistency in this experiment; however, Amado et al. (2019) indicated a better fecal consistency with HF versus HL CMR. Additionally, Wilms et al. (2019) has shown that higher CMR osmolality may lead to higher gut permeability. With exchanging lactose for fat, CMR osmolality is reduced and would reduce gut permeability (Wilms et al., 2019). To the contrary, however, Amado et al. (2019) showed a higher gut permeability with HF CMR. The current experiment indicated a reduced occurrence of healthrelated events with HF CMR, although these events were mainly respiratory and not digestive. There have been other indications that a higher nutrient supply in calves fed a high plane of nutrition influences immunity and health, also related to respiratory health and even still present after weaning (Nonnecke et al., 2003; Ballou, 2012; Ballou et al., 2015).

\section{Blood Traits}

Components in blood with a significant overall treatment difference $(P<0.01)$ were phosphate, NEFA, 


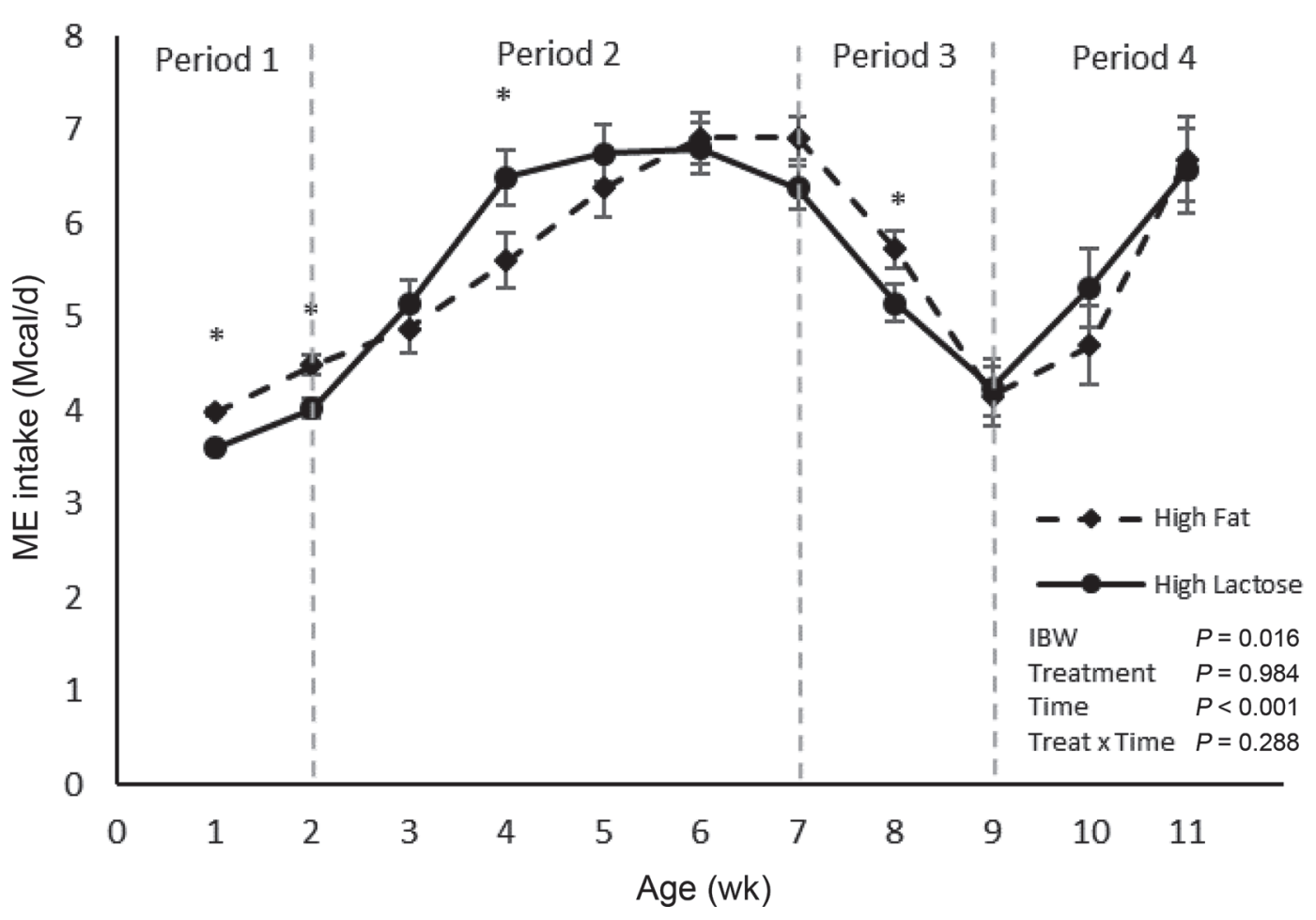

Figure 4. Estimated ME intake from starter and calf milk replacer (CMR) in calves $(\mathrm{n}=32)$ fed a high-fat (dashed) or a high-lactose (solid) CMR across periods 1 to 4 . Asterisks indicate significant differences $(P<0.05)$ between the 2 treatments (unstructured covariance matrix, without block effect). Period 1: CMR restricted; period 2: CMR ad libitum; period 3: weaning; period 4: postweaning. IBW = initial BW. Error bars indicate SEM.

triacylglycerides, total bilirubin, and hemolysis. In the current trial, HF had higher phosphate levels than HL. Animals that have low phosphate at birth $(<2.26$ $\mathrm{mmol} / \mathrm{L})$ have been shown to have greater risk for diarrhea, with scouring calves having lower phosphate status than healthy calves up to $20 \mathrm{~d}$ of age (Jagoš et al., 1981, citing Cabello et al., 1977). Amado et al. (2019) found higher fecal consistency (i.e., less thin) in the first week after birth when feeding high fat.

Increased triglyceride and NEFA content in blood for the HF diet seemed to be a direct result of the higher inclusion of fat. The higher blood NEFA levels likely contribute to the lower intake in HF through NEFA oxidation in the liver (Allen, 2014). Surprisingly, for triglycerides, this effect was numerically persistent until $84 \mathrm{~d}$ of age, which was $14 \mathrm{~d}$ after animals had been totally weaned.

The HF animals had higher bilirubin and hemolysis values than HL animals. Bilirubin is a product of the breakdown of hemoglobin and is excreted in the gut. Increased bilirubin content in blood could be an indicator of hemolysis (which was also higher for high fat) or different liver metabolism and has been associated with health conditions (Klinkon and Jezek, 2012). However, the current values fell well within, and the differences in bilirubin between treatments were minor relative to, the reference values for healthy female calves as published by Lumsden et al. (1980). Therefore, although

Table 3. Effect of calf milk replacer composition [high fat (HF) vs. high lactose (HL)] on health interventions from birth until $77 \mathrm{~d}$ of age in dairy calves $(\mathrm{n}=32)$

\begin{tabular}{|c|c|c|c|c|}
\hline Item & $\mathrm{HF}$ & HL & $\mathrm{SE}$ & $\begin{array}{c}\text { HF vs. HL } \\
P \text {-value }\end{array}$ \\
\hline Days with therapeutic intervention & 2.13 & 5.63 & 1.104 & 0.018 \\
\hline No. of therapeutic interventions ${ }^{1}$ & 2.00 & 4.56 & 0.699 & 0.010 \\
\hline No. of disease events that needed therapeutic intervention ${ }^{2}$ & 1.00 & 2.25 & 0.319 & 0.011 \\
\hline
\end{tabular}

${ }^{1}$ Number of therapeutic interventions given to a calf during the study.

${ }^{2}$ Number of disease events that needed medical treatment according a predetermined health protocol (see Supplemental File S1; https://doi.org/10.3168/jds.2019-17382). 


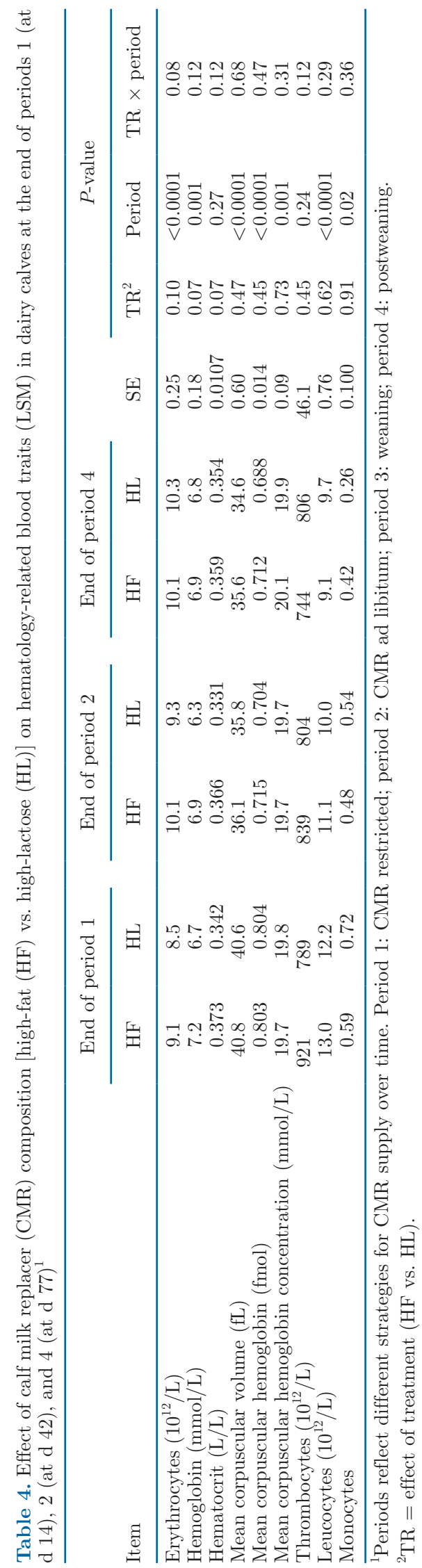

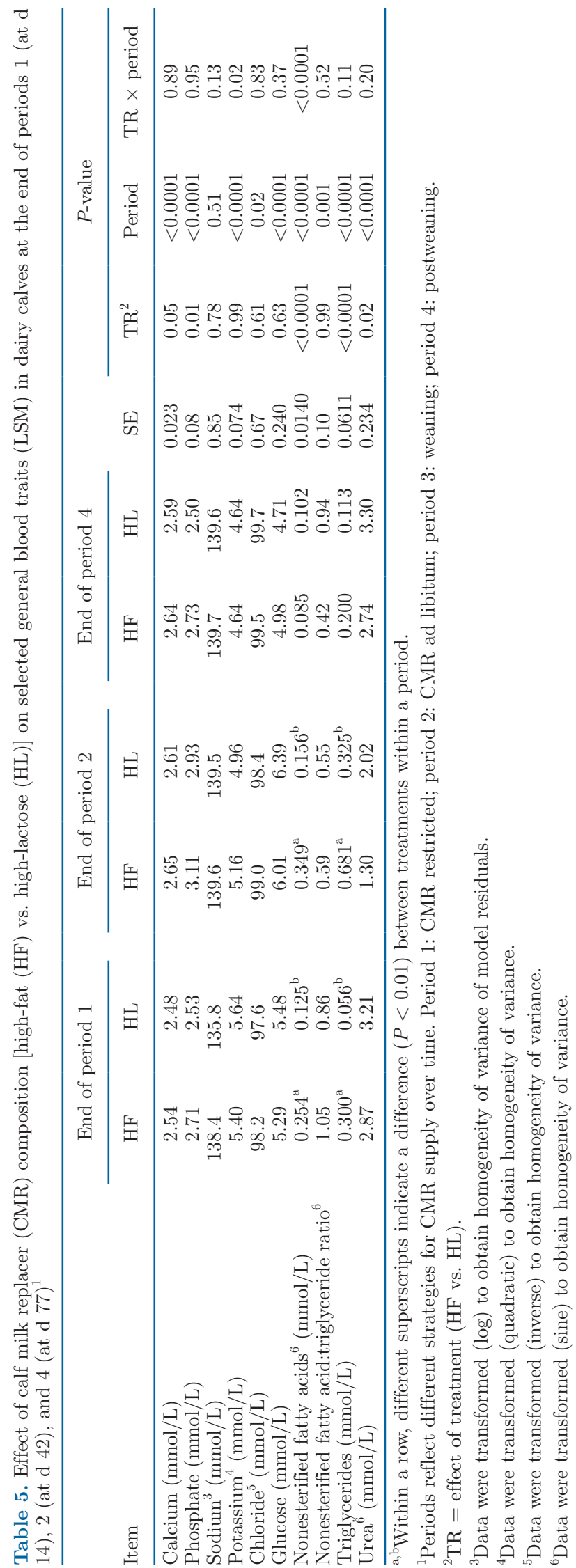




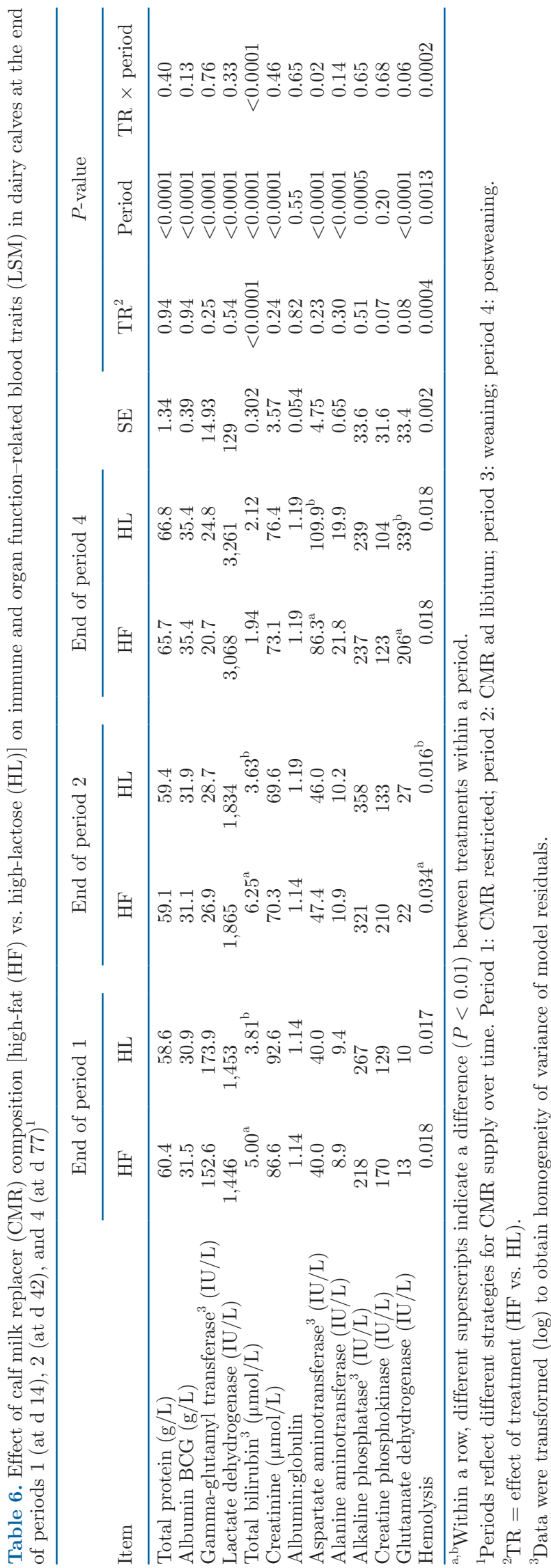

the nutrition of the calves that were the basis for these references values is unknown, it is unlikely that the differences in bilirubin were reflective of an adverse condition.

Despite the substantial difference in daily glucose supply, plasma glucose remained unaffected by dietary treatment at all ages. In an earlier study, exchanging lactose for fat in CMR for veal calves of 14 to $27 \mathrm{wk}$ of age, Pantophlet et al. (2016) observed a difference in postprandial glucose response (up to $240 \mathrm{~min}$ ), whereas there was no effect on fasting plasma glucose concentration. Blood samples in the current experiment were taken at $1000 \mathrm{~h}$, which in period 1 was 3 to $4 \mathrm{~h}$ after morning feeding. However, in period 2 calves were on automatic feeders and thus able to consume CMR throughout the day. It was therefore not possible to establish whether the blood values measured were still part of a postprandial response or basal metabolism.

\section{CONCLUSIONS}

Under these experimental conditions, where calves were allowed ad libitum access to a CMR from $14 \mathrm{~d}$ of age, increasing fat content at the expense of lactose decreased CMR intake by 10\%, whereas ME intake and growth remained equal between treatments. Solid feed (starter and straw) consumption was not significantly affected by CMR energy source. These data indicate that calves fed ad libitum regulated CMR intake to their energy demands for growth. The HF CMR increased plasma phosphate, NEFA, triglycerides, and bilirubin, whereas plasma glucose remained unchanged. Although animal numbers were limited in the present experiment, there was a decrease in the number of therapeutic interventions needed and the number of therapeutic interventions in calves observed with the HF CMR. These interventions were mainly related to respiratory disease. This study provides information on the voluntary intake of CMR as affected by energy source. Calves appeared to drink CMR to fulfil their energy requirements, and increased fat content at the expense of lactose in CMR resulted in an improved feed conversion (milk replacer intake based) with equivalent BW gain and solid feed intake.

\section{ACKNOWLEDGMENTS}

The authors thank Natasja Boots and Mieke LangenThijssen from Trouw Nutrition R\&D, and the staff of the Trouw Nutrition Calf and Beef Research facility (St. Anthonis, the Netherlands) for their skilled technical assistance. H. Berends, H. van Laar, L. N. Leal, and J. Martin-Tereso work at Trouw Nutrition, a company with interest in the animal nutrition sector. 


\section{REFERENCES}

Allen, M. S. 1996. Physical constraints on voluntary intake of forages by ruminants. J. Anim. Sci. 74:3063-3075. https://doi.org/10 $.2527 / 1996.74123063 x$.

Allen, M. S. 2014. Drives and limits to feed intake in ruminants. Anim. Prod. Sci. 54:1513-1524. https://doi.org/10.1071/AN14478.

Amado, L., H. Berends, L. N. Leal, J. Wilms, H. Van Laar, W. J. J. Gerrits, and J. Martín-Tereso. 2019. Effect of energy source in calf milk replacer on performance, digestibility and gut permeability in rearing calves. J. Dairy Sci. 102:3994-4001. https://doi.org/10 .3168/jds.2018-15847.

Atwood, S. B., F. D. Provenza, R. D. Wiedmeier, and R. E. Banner. 2001. Influence of free-choice vs. mixed-ration diets on food intake and performance of fattening calves. J. Anim. Sci. 79:3034-3040. https://doi.org/10.2527/2001.79123034x.

Bach, A. 2011. Associations between several aspects of heifer development and dairy cow survivability to second lactation. J. Dairy Sci. 94:1052-1057. https://doi.org/10.3168/jds.2010-3633.

Bach, A. 2012. Ruminant Nutrition Symposium: Optimizing performance of the offspring: Nourishing and managing the dam and postnatal calf for optimal lactation, reproduction, and immunity. J. Anim. Sci. 90:1835-1845. https://doi.org/10.2527/jas.2011 $-4516$.

Bado, A., S. Levasseur, S. Attoub, S. Kermorgant, J. P. Laigneau, M. N. Bortoluzzi, L. Moizo, T. Lehy, M. Guerre-Millo, Y. Le Marchand-Brustel, and M. J. Lewin. 1998. The stomach is a source of leptin. Nature 394:790-793. https://doi.org/10.1038/29547.

Ballou, M. A. 2012. Immune responses of Holstein and Jersey calves during the preweaning and immediate postweaned periods when fed varying planes of milk replacer. J. Dairy Sci. 95:7319-7330. https://doi.org/10.3168/jds.2012-5970.

Ballou, M. A., D. L. Hanson, C. J. Cobb, B. S. Obeidat, M. D. Sellers, A. R. Pepper-Yowell, J. A. Carroll, T. J. Earleywine, and S. D. Lawhon. 2015. Plane of nutrition influences the performance, innate leukocyte responses, and resistance to an oral Salmonella enterica serotype Typhimurium challenge in Jersey calves. J. Dairy Sci. 98:1972-1982. https://doi.org/10.3168/jds.2014-8783.

Bar-Peled, U., B. Robinzon, E. Maltz, H. Tagari, Y. Folman, I. Bruckental, H. Voet, H. Gacitua, and A. R. Lehrer. 1997. Increased weight gain and effects on production parameters of Holstein heifer calves that were allowed to suckle from birth to six weeks of age. J. Dairy Sci. 80:2523-2528. https://doi.org/10.3168/jds.S0022 -0302(97)76205-2.

Bartlett, K. S., F. K. McKeith, M. J. VandeHaar, G. E. Dahl, and J. K. Drackley. 2006. Growth and body composition of dairy calves fed milk replacers containing different amounts of protein at two feeding rates. J. Anim. Sci. 84:1454-1467. https://doi.org/10 $.2527 / 2006.8461454 \mathrm{x}$.

Bascom, S. A., R. E. James, M. L. McGilliard, and M. Van Amburgh. 2007. Influence of dietary fat and protein on body composition of Jersey bull calves. J. Dairy Sci. 90:5600-5609. https://doi.org/10 .3168/jds.2007-0004.

Benjamini, Y., and Y. Hochberg. 1995. Controlling the false discovery rate: A practical and powerful approach to multiple testing. J. R. Stat. Soc. B 57:289-300. https://doi.org/10.1111/j.2517-6161.1995 .tb02031.x.

Berends, H., W. J. J. Gerrits, L. E. Webb, E. A. M. Bokkers, and C. G. van Reenen. 2016. Determinants of feed preferences and intake in calves. Pages 97-98 in Energy and Protein Metabolism and Nutrition. EAAP publication no. 137. Wageningen Academic Publishers, Wageningen, the Netherlands.

Cabello, G., M. C. Michel, C. Foucher, and C. Lafarge. 1977. Composition of blood plasma (calcium, phosphorus, magnesium, proteins) during the neonatal period in the calf. Influence of the state of health. Ann. Rech. Vet. 8:203-211.

de Passillé, A. M., and J. Rushen. 1997. Motivational and physiological analysis of the causes and consequences of non-nutritive sucking by calves. Appl. Anim. Behav. Sci. 53:15-31. https://doi.org/ 10.1016/S0168-1591(96)01148-3. de Paula, M. R., C. E. Oltramari, J. T. Silva, M. P. C. Gallo, G. B. Mourão, and C. M. M. Bittar. 2017. Intensive liquid feeding of dairy calves with a medium crude protein milk replacer: Effects on performance, rumen, and blood parameters. J. Dairy Sci. 100:4448-4456. https://doi.org/10.3168/jds.2016-10859.

Diaz, M. C., M. E. Van Amburgh, J. M. Smith, J. M. Kelsey, and E. L. Hutten. 2001. Composition of growth of Holstein calves fed milk replacer from birth to 105-kilogram body weight. J. Dairy Sci. 84:830-842. https://doi.org/10.3168/jds.S0022-0302(01)74541-9.

Donnelly, P. E. 1983. Effects of dietary carbohydrate:fat ratio on growth and body composition of milk-fed calves. N. Z. J. Agric. Res. 26:71-77. https://doi.org/10.1080/00288233.1983.10420953.

Etheridge, R., G. Pesti, and E. Foster. 1998. A comparison of nitrogen values obtained utilizing the Kjeldahl nitrogen and Dumas combustion methodologies (Leco CNS 2000) on samples typical of an animal nutrition analytical laboratory. Anim. Feed Sci. Technol. $73: 21-28$.

European Commission. 1971. Directive 71/250/EEG. Methods of analysis for the official control of feeding stuffs. Off. J. L155:13-37.

European Commission. 2009. Directive 152/2009. Commission regulation laying down the methods of sampling and analysis for the official control of feed. Off. J. L54:1-130.

European Commission. 2010. Directive 2010/63/EU of the European parliament and of the council of 22 September 2010 on the protection of animals used for scientific purposes. Off. J. L276:33-79.

Esselburn, K. M., K. M. O'Diam, T. M. Hill, H. G. Bateman II, J. M. Aldrich, R. L. Schlotterbeck, and K. M. Daniels. 2013. Intake of specific fatty acids and fat alters growth, health, and titers following vaccination in dairy calves. J. Dairy Sci. 96:5826-5835. https:/ /doi.org/10.3168/jds.2013-6608.

Frayn, K. N., F. Karpe, B. A. Fielding, I. A. MacDonald, and S. W. Coppack. 2003. Integrative physiology of human adipose tissue. Int. J. Obes. Relat. Metab. Disord. 27:875-888. https://doi.org/10 $.1038 /$ sj.ijo.0802326.

Gerrits, W. J. J. 2019. Symposium review: Macronutrient metabolism in the growing calf. J. Dairy Sci. 102:3684-3691. https://doi.org/ $10.3168 /$ jds.2018-15261.

Haley, D. B., J. Rushen, I. J. H. Duncan, T. M. Widowski, and A. M. De Passillé. 1998. Effects of resistance to milk flow and the provision of hay on non-nutritive sucking by dairy calves. J. Dairy Sci. 81:2165-2172. https://doi.org/10.3168/jds.S0022-0302(98)75794 -7 .

Hill, S. R., K. F. Knowlton, K. M. Daniels, R. E. James, R. E. Pearson, A. V. Capuco, and R. M. Akers. 2008. Effects of milk replacer composition on growth, body composition, and nutrient excretion in preweaned Holstein heifers. J. Dairy Sci. 91:3145-3155. https:/ /doi.org/10.3168/jds.2007-0860.

Hof, G. 1980. An investigation into the extent to which various dietary components, particularly lactose, are related to the incidence of diarrhoea in milk-fed calves. PhD Thesis. Wageningen University, Wageningen, the Netherlands.

Jagoš, P., V. Dvorak, and J. Bouda. 1981. Levels of minerals in the blood plasma of cows and their calves fed from the bucket. Acta Vet. Brno 50:33-41. https://doi.org/10.2754/avb198150010033.

Jaster, E. H., G. C. McCoy, N. Spanski, and T. Tomkins. 1992. Effect of extra energy as fat or milk replacer solids in diets of young dairy calves on growth during cold weather. J. Dairy Sci. 75:2524-2531. https://doi.org/10.3168/jds.S0022-0302(92)78014-X.

Khan, M. A., A. Bach, D. M. Weary, and M. A. G. von Keyserlingk. 2016. Invited review: Transitioning from milk to solid feed in dairy heifers. J. Dairy Sci. 99:885-902. https://doi.org/10.3168/jds.2015 $-9975$.

Khan, M. A., D. M. Weary, and M. A. von Keyserlingk. 2011. Invited review: Effects of milk ration on solid feed intake, weaning, and performance in dairy heifers. J. Dairy Sci. 94:1071-1081. https:// doi.org/10.3168/jds.2010-3733.

Klinkon, M., and J. Jezek. 2012. Values of blood variables in calves. Pages 301-320 in A Bird's-Eye View of Veterinary Medicine. C. C. Perez-Marin, ed. InTech, Rijeka, Croatia.

Korst, M., C. Koch, J. Kesser, U. Müller, F.-J. Romberg, J. Rehage, K. Eder, and H. Sauerwein. 2017. Different milk feeding intensi- 
ties during the first 4 weeks of rearing in dairy calves: Part 1: Effects on performance and production from birth over the first lactation. J. Dairy Sci. 100:3096-3108. https://doi.org/10.3168/ jds.2016-11594.

Lumsden, J. H., K. Mullen, and R. Rowe. 1980. Hematology and biochemistry reference values for female Holstein cattle. Can. J. Comp. Med. 44:24-31.

MacPherson, J. A. R., H. Berends, L. N. Leal, J. P. Cant, J. MartínTereso, and M. A. Steele. 2016. Effect of plane of milk replacer intake and age on glucose and insulin kinetics and abomasal emptying in female Holstein Friesian dairy calves fed twice daily. J. Dairy Sci. 99:8007-8017. https://doi.org/10.3168/jds.2015-10826.

Meale, S. J., F. Chaucheyras-Durand, H. Berends, L. L. Guan, and M. A. Steele. 2017. From pre- to postweaning: Transformation of the young calf's gastrointestinal tract. J. Dairy Sci. 100:5984-5995. https://doi.org/10.3168/jds.2016-12474.

Moallem, U., D. Werner, H. Lehrer, M. Zachut, L. Livshitz, S. Yakoby, and A. Shamay. 2010. Long-term effects of ad libitum whole milk prior to weaning and prepubertal protein supplementation on skeletal growth rate and first-lactation milk production. J. Dairy Sci. 93:2639-2650. https://doi.org/10.3168/jds.2009-3007.

Morrison, S. J., H. C. F. Wicks, A. F. Carson, R. J. Fallon, J. Twigge, D. J. Kilpatrick, and S. Watson. 2012. The effect of calf nutrition on the performance of dairy herd replacements. Animal 6:909-919. https://doi.org/10.1017/S1751731111002163.

National Research Council. 2001. Nutrient Requirements of Dairy Cattle. 7th rev. ed. Natl. Acad. Press, Washington, DC.

Nonnecke, B. J., M. R. Foote, J. M. Smith, B. A. Pesch, and M. E. Van Amburgh. 2003. Composition and functional capacity of blood mononuclear leukocyte populations from neonatal calves on standard and intensified milk replacer diets. J. Dairy Sci. 86:35923604. https://doi.org/10.3168/jds.S0022-0302(03)73965-4.

Pantophlet, A. J., W. J. J. Gerrits, R. J. Vonk, and J. J. G. C. van den Borne. 2016. Substantial replacement of lactose with fat in a high-lactose milk replacer diet increases liver fat accumulation but does not affect insulin sensitivity in veal calves. J. Dairy Sci. 99:10022-10032. https://doi.org/10.3168/jds.2016-11524.

Raeth-Knight, M., H. Chester-Jones, S. Hayes, J. Linn, R. Larson, D. Ziegler, B. Ziegler, and N. Broadwater. 2009. Impact of conventional versus intensive milk replacer programs on Holstein heifer performance through six months of age and during first lactation. J. Dairy Sci. 92:799-809. https://doi.org/10.3168/jds.2008-1470.

Rijnen, M. M. J. A., M. W. A. Verstegen, M. J. W. Heetkamp, and J. W. Schrama. 2001. Effects of dietary fermentable carbohydrates on energy metabolism in group-housed sows. J. Anim. Sci. 79:148154.

Soberon, F., and M. E. Van Amburgh. 2013. Lactation Biology Symposium: The effect of nutrient intake from milk or milk replacer of preweaned dairy calves on lactation milk yield as adults: A meta-analysis of current data. J. Anim. Sci. 91:706-712. https:// doi.org/10.2527/jas.2012-5834.

Tikofsky, J. N., M. E. Van Amburgh, and D. A. Ross. 2001. Effect of varying carbohydrate and fat content of milk replacer on body composition of Holstein bull calves. J. Anim. Sci. 79:2260-2267. https://doi.org/10.2527/2001.7992260x.

van den Borne, J. J., G. E. Lobley, M. W. A. Verstegen, J.-M. Muijlaert, S. J. Alferink, and W. J. J. Gerrits. 2007. Body fat deposition does not originate from carbohydrates in milk-fed calves. J. Nutr. 137:2234-2241. https://doi.org/10.1093/jn/137.10.2234.

Weary, D. M., J. Jasper, and M. J. Hötzel. 2008. Understanding weaning distress. Appl. Anim. Behav. Sci. 110:24-41. https://doi.org/ 10.1016/j.applanim.2007.03.025.

Webb, L. E., B. Engel, H. Berends, C. G. van Reenen, W. J. J. Gerrits, I. J. M. de Boer, and E. A. M. Bokkers. 2014. What do calves choose to eat and how do preferences affect behaviour? Appl. Anim. Behav. Sci. 161:7-19. https://doi.org/10.1016/j.applanim .2014.09.016.

Wilms, J., H. Berends, and J. Martin-Tereso. 2019. Hypertonic milk replacers increase gastrointestinal permeability in healthy dairy calves. J. Dairy Sci. 102:1237-1246. https://doi.org/10.3168/jds .2018-15265.

Yonekura, S., K. Kitade, G. Furukawa, K. Takahashi, N. Katsumata, K. Katoh, and Y. Obara. 2002. Effects of aging and weaning on mRNA expression of leptin and CCK receptors in the calf rumen and abomasum. Domest. Anim. Endocrinol. 22:25-35. https://doi .org/10.1016/s0739-7240(01)00114-x.

\section{ORCIDS}

H. Berends ๑ https://orcid.org/0000-0003-0535-5575

H. van Laar @ https://orcid.org/0000-0002-4156-1512

L. N. Leal ๑ https://orcid.org/0000-0002-7798-3995

W. J. J. Gerrits ๑ https://orcid.org/0000-0003-0494-9259

J. Martín-Tereso () https://orcid.org/0000-0002-6757-4629 